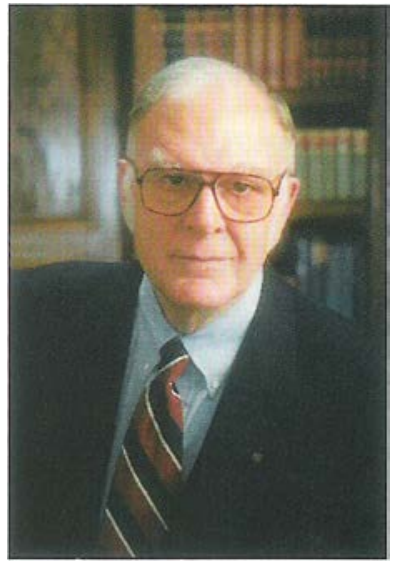

F. Sherwood Rowland

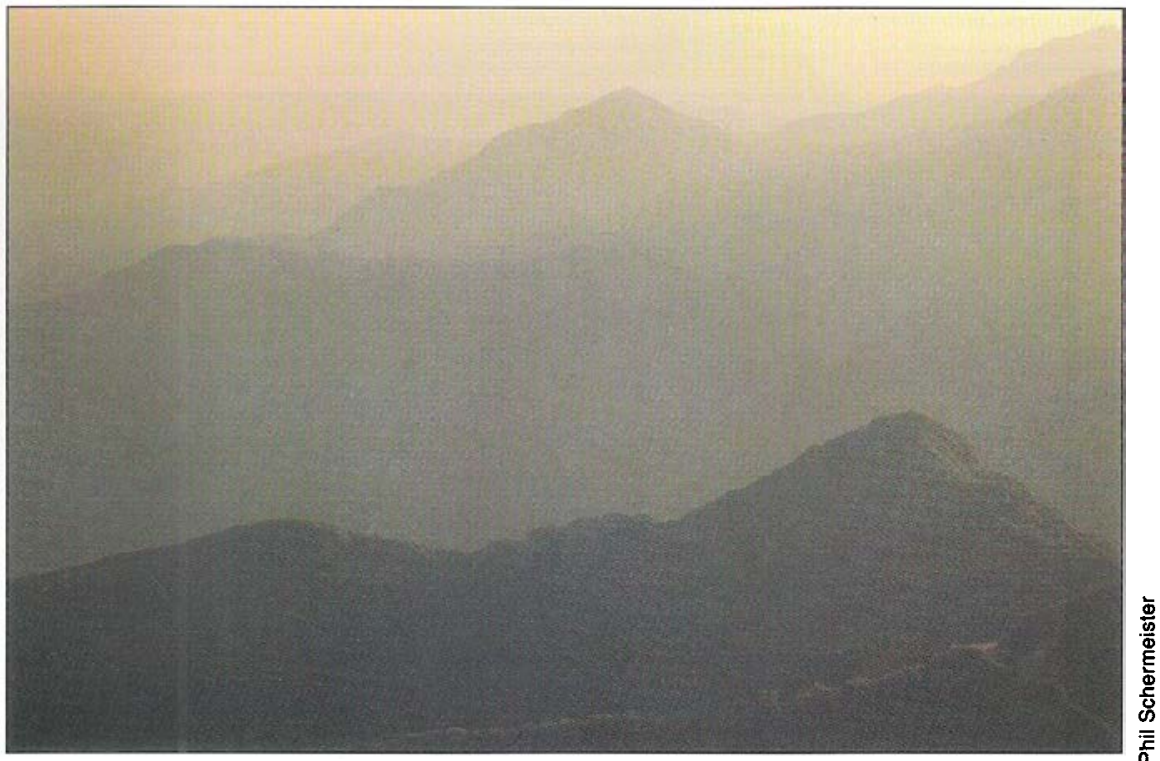

The amount of carbon dioxide released per person in the United States has increased in each of the past $\mathbf{5 0}$ years, contributing to global warming. In Sequoia National Park, air pollution is visible from Moro Rock.

\title{
Global warming: No easy answers
}

Editor's note: Growing evidence worldwide indicates that human activity, particularly fossil-fuel consumption, is warming up the planet. Scientists recently reported that the Arctic ice sheet, covering an area roughly the size of the United States, had shrunk by about $6 \%$ between 1978 and 1996. In another recent report, scientists who rescued and digitized decades of ocean temperature data have confirmed that much of the heat trapped by greenhouse gases is going into the world's oceans. Finally, Antarctica, home to $91 \%$ of Earth's ice cover, is also melting; within the past decade, three ice shelves have fully disintegrated and icebergs the size of Delaware have broken off.

California Agriculture Executive Editor Janet White spoke with F. Sherwood Rowland, Donald Bren Research Professor of Chemistry and Earth System Science at UC Irvine. In 1995, Rowland shared the Nobel Prize in Chemistry with Mario Molina and Paul Crutzen "for their work in atmospheric chemistry, particularly concerning the formation and decomposition of ozone." Rowland shared his thoughts about how humans have altered the Earth's atmosphere, what the future holds and what can be done.

\section{Has the Earth warmed up in recent years?}

The globally averaged surface temperature has increased by about $1.1^{\circ} \mathrm{F}$ since 1880 , and most of the warmest years have been in the 1990s, with 1998 the warmest and the decade of the 1990s easily the warmest in this record. In contrast, the stratosphere has cooled slightly because the composition changes do not affect all of the atmosphere uniformly. For humans, the surface temperature affects how we spend our lives, where agriculture takes place and where our water supply collects.

Assuming that greenhouse gases are causing enhanced global warming, and greenhouse gases double as expected by the end of the 21st century, model calculations indicate the Earth's surface temperatures could increase $2^{\circ} \mathrm{F}$ to $6^{\circ} \mathrm{F}$.

\section{Why is the situation getting worse?}

Much of the improvement in lifestyles in the United States over the past century has depended upon the availability of energy sources other than human or animal - electricity, for instance. Most of these additional energy sources depend ultimately upon the burning of fossil fuels, with the release of carbon dioxide to the atmosphere. The amount of carbon dioxide released per person in the United States each year has increased over the past 50 years, as it has in most countries of the world. However, the per capita release of carbon dioxide is more than 5 tons per year in the United States versus 0.2 tons per year in India. The global population has increased from 1.6 billion in 1900 to 6 bil- 


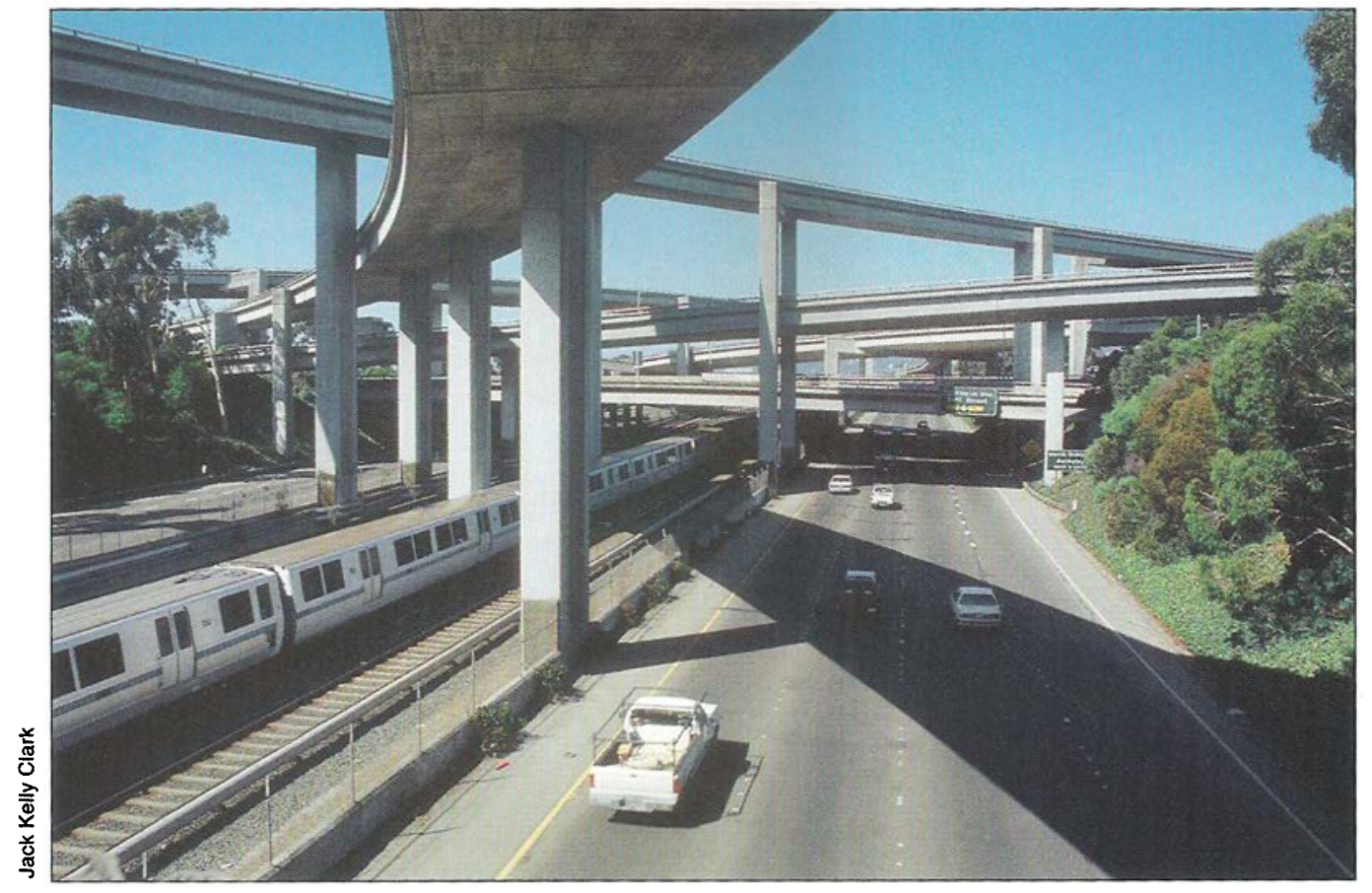

While clean-burning fuels have reduced urban smog, carbon atoms from gasoline combustion still end up in the environment and contribute to global warming. An escalating carbon tax would promote more fuel-efficient transportation. lion in 1999, and is continuing to rise. The environmental pressure has increased quite substantially and continues to grow.

\section{What are the causes of climate change?}

Climate change is caused by an alteration of the chemical composition of Earth's atmosphere by various activities of humankind. The physical mechanism depends on making it more difficult for infrared radiation from Earth to escape to space.

A few percent of the incoming solar energy arrives as invisible ultraviolet radiation, with about half of the rest in the visible (violet to red) and the remainder as infrared radiation, also invisible. The cooler an object, the less energy it gives off and the peak wavelengths shift from violet to yellow (the sun) to red, and then to infrared. Because the surface temperature of the Earth is much cooler than the sun, the energy escaping from the Earth is emitted at much longer wavelengths (the "far infrared"). However, some of these wavelengths can be strongly absorbed by atmospheric molecules which contain three or more atoms, such as carbon dioxide, methane, water vapor, ozone, nitrous oxide and the chlorofluorocarbons (CFCs). (The less complex main components of the atmosphere, nitrogen, oxygen and argon, are transparent to infrared radiation.)

While all of these except the CFCs are natural components of the atmosphere, most are also released by activities of humankind and their atmospheric concentrations have been steadily increasing. For example, carbon diox- ide is the end-product from the combustion of coal, gas and oil, and methane is released from water-covered rice plants and from cows and other animals.

\section{What is the greenhouse effect?}

If all the planetary infrared escapes into space, the calculated surface temperature of the Earth is $0^{\circ} \mathrm{F}$. Yet the actual average surface temperature of the Earth is about $57^{\circ} \mathrm{F}$. This $57^{\circ}$ difference is the natural greenhouse effect, and is explained by the absorption of some outgoing far-infrared radiation by molecules in the natural atmosphere. When the escape route is partially blocked by these gases, the planet warms up to produce enough infrared emissions in the unblocked wavelengths, allowing the escaping energy to equal the incoming solar radiation.

The present concern is really about an enhanced greenhouse effect from the accumulation of more of these greenhouse gases. While a few degrees may not seem like much, the ice ages with New England, the Great Lakes and all of Canada under as much as a mile of solid ice were only about $10^{\circ} \mathrm{F}$ cooler than now. An Earth warmer than the present will be very different, with rising oceans, more intense storms and many other changes.

\section{How will global climate change affect California's water supply?}

It's difficult to provide a precise answer, but two factors about California's water supply are likely to hold. First, warmer water evaporates faster. With a warmer planet, more water will evaporate, condense into droplets and return as rain. Second, as the planet warms more precipitation will come down on the rain side of the rain/snow divide, and the snow that does fall will melt sooner. For California, this should result in a higher fraction of immediate runoff versus accumulation as snowpack. The increased total precipitation should mean considerably more river runoff in the winter, and perhaps smaller snowpacks and less summer availability of water. A lot of California land is not far above sea level, so rising oceans will be a 
concern both for flooding and salinity. Conversely, in the Midwest the hotter summers will probably make the land dryer.

\section{What will the situation be like in 2025?}

During the next 25 years many possibilities exist, each of which can slightly reduce the overall magnitude of the greenhouse-gas problem. First and foremost, energy can be used with much greater efficiency, and that's good for everyone. An escalating carbon tax - a 15cent-per-gallon increase per year for 15 years, for example - would induce everyone, manufacturers and customers alike, to look for more fuel-efficient transportation. Minor energy sources such as solar cells and windmills can be developed where appropriate. Nuclear power will undoubtedly continue to be used in many countries, and may grow substantially if the radioactive waste problem is solved satisfactorily. Controlled power from nuclear fusion remains a distant but perhaps unreachable goal.

However, none of these are going to cause big reductions in the demand for fossil-fuel power plants, so the atmospheric concentration of carbon dioxide will increase steadily during this period. Once it's there, removal of excess carbon dioxide is a centuries-long process.

\section{Is there a solution to global warming?}

About $85 \%$ of the world's industrial energy comes from the combustion of coal, gas and oil. Nuclear and hydroelectric power make up most of the rest, with solar cells, windmills and the other sources making up no more than $1 \%$ or $2 \%$. Because the useful life of a power plant is typically 3 to 5 decades, the patterns of worldwide industrial energy use take decades to change.

On the other hand, the automotive fleet averages lifetimes of about 15 years, so can be improved more rapidly. The combustion of gasoline is often done inefficiently, leaving carbon in the form of carbon monoxide or small reactive hydrocarbons such as acetylene and ethylene. These contribute heavily to urban smog and cause difficulties both within the cities and for hundreds of miles downwind. New and welltuned cars now burn gasoline very efficiently, helping greatly with the urban smog problem. Ultimately, however, these carbon atoms from gasoline still end up as carbon dioxide, so that clean-burning automobiles reduce smog but have no effect on global warming.
In the next 50 years some solutions are possible. The capture of carbon dioxide immediately after its formation in a power plant could be done now, but it would be very expensive with current technology, and then what would you do with it? The tonnage of such waste in liquid or solid form would be even larger than that of the coal, oil and gas going in. Nevertheless, capture of carbon dioxide at the powerplant source followed by storage either belowground or in the deep ocean, called sequestration, is now under serious investigation. Such studies are in their earliest stages. The entire process of sequestration will always be more expensive than simple release to the atmosphere, and the storage location would need to be secure against accidental release to the atmosphere for many centuries.

\section{Is there international agreement on how to control climate change?}

A United Nations Conference in Rio de Janeiro agreed in 1992 to work out a mechanism for control of greenhouse-gas emissions, but limited it at present to the industrial countries of the developed world. An agreement was reached in Kyoto in 1997 for such controls on four individual gases plus two generic gas classes, with carbon dioxide at the top of the list. (The gases include carbon dioxide, methane, nitrous oxide, sulfur hexafluoride, hydrofluorocarbons and perfluorocarbons.) The agreement has not been ratified by the United States and many other countries. The Kyoto agreement called only for The increased total precipitation should mean considerably more river runoff in the winter, and perhaps, because of the shift from snow to rain, smaller snowpacks and less summer availability of water.

a rollback in emissions to a few percent below the 1990 levels. Even if fully ratified and every country were observing the specified limits, greenhouse gases would still be accumulating steadily in the atmosphere because most of the gases once released to the atmosphere remain for decades to centuries.

\section{What is UC's role?}

The climate problem has so many facets to it - scientific, technological, economic, social, legal, regulatory - that the expertise of a very large fraction of the UC community is potentially involved. And, of course, as the climate changes, everyone is affected directly or indirectly. 